\title{
Perspectives on gender parity in bioanalysis: an interview with Shefali Patel
}

Shefali R Patel*,1

${ }^{1}$ Janssen R\&D, 1400 McKean road, Springhouse, PA 19477, USA

*Author for correspondence: spatel31@its.jnj.com

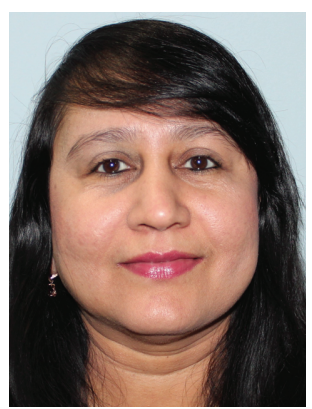

\section{Biography:}

Shefali R Patel is a Senior Scientist and a Group leader in the Bioanalytical Group within DMPK Department at Janssen (a Johnson \& Johnson company). In her current role, she is supervising the nonregulated bioanalysis group within East Coast Bioanalytical Department. Also, as a part of her current role, she is applying microsampling techniques for rodent studies within Johnson \& Johnson. She has 17 years of experience in Bioanalytical Sciences. Before joining Janssen in 2007, Shefali was a Research Chemist with Drug Metabolism Department for Merck Research Laboratories in Rahway, NJ, USA. Prior to Merck, she was employed as Scientist with Taylor Technology (CRO) in Princeton, NJ, USA.

Accepted for publication: 5 March 2019; Published online: 18 April 2019

\section{How can mentors help women in their career development?}

When I joined an organization years ago, they had a program called 'first friend' in which a person was assigned to help you while you started a new role. This first friend helped you with anything you needed or any questions you might have when you started a new role in the organization. First friend also guided you through the trainings, IT access as well as organization culture. For some, their first friends became their mentors going forward.

I personally have mentors in different departments and organizations independent of their levels, job roles or gender. These are the people you can go to or pick up a phone and talk to when you really need any help whether it is work related or not. Even if you have moved to different companies these are the people you send an email or make a phone call when you have any questions or need any guidance. They can be a sounding board for any ideas you may have and can give you valuable advice to build your own professional knowledge and network. You can learn new ways of thinking from your mentor and they probably benefit from mentoring you as well. When you start a new role or when you need any help in your current role, mentors can help identify your strengths/weakness or can guide you to develop your skillsets.

We probably do not realize that we all have mentors knowingly or unknowingly. With an everchanging, fast paced workplace we often need to learn, unlearn and relearn things. With mentors on our side, we can find ways to facilitate new learnings, expand our network and embrace innovative ideas.

\section{How important it is to have short-term \& long-term goals in your career?}

Building a career plan is crucial for any professional (new career or experienced professionals), since it acts as a beacon to keep you motivated, determined and focused on your self-guided path. In my opinion, you should have short-term, mid-term as well as long-term goals. Short-term goals can be immediate, from 1 week to 1 year while mid-term goals can be from 1 to 5 years. Long-term goals can range from 5 to 20 years or beyond. When we start our new careers we sometimes think of short- or mid-term goals only. Long-term goals are often neglected until we reach 3-5 years in our career and then we get serious about our career goals or where we want to be. You can always start as - where I am in my current career, what I would like to do in the future and what it would take me (trainings, courses, new skillsets, etc.) to reach my future career/goals. When you start envisioning where you want to see yourself in your career, you start to design a game plan or map out a strategy that will bring you closer to achieve your goals/dreams. After few years in our current career, we all reach a plateau, which means your capabilities in that current role increase while your growth opportunities in that area decrease. For that reason, we 
should identify and focus on new skill sets or experiences which will take us to a new level and will help us grow in personal and professional development.

Keep in mind that all the goal settings are flexible and can be turned into short/mid/long term or moved around or combined (mid/long term) since you are the driver of your own goals/career. No matter how well thought the career plans/goals are they always do not work out the way you have planned. Therefore, it is essential to be flexible with alternate paths if need arises but no matter the outcome you should be thinking about your career and have game plan/strategy.

\section{What are the most valuable skill sets women/diversity bring to an organization?}

Workplace diversity in general is not limited to hire more specific gender but team of colleagues with different work styles, various levels of experiences and diverse cultures or generations all working with a one team/one goal approach in an organization. Considering more women in your workplace is a whole separate set of discussion which often gets overlooked in a big picture. Few skills set to name which specifically women bring to table include listening skills, multitasking, opportunity experts, networking specialists as well as collaborative approaches to problem solving.

We all have our own talents, assorted attributes and diverse skillsets which we bring to a team environment without which it would be hard for any team to develop, innovate or progress. Biggest benefit of a diverse organization is the ability to tap into a pool of talent with employees from different background, capabilities, perspectives and concepts they bring to the workplace. In general, more and more companies are now committing to hiring diverse talents including hiring more women because the long-term success of any organization depends on innovative ideas, diverse views and a right mindset.

\section{How do you mange work/life balance in your busy schedule \& what advice would you like to give to young women who are starting their careers?}

Work/life balance is when you split your time and energy between work and other important aspects of your life including but not limited to self-care, family, friends, personal growth and other personal activities. With a competitive marketplace, busy schedules and demanding workload, we are now more engaged at work, so it gets tough to maintain the balance between work and personal life, especially when you have a family which requires your attention. We all know that as a parent, childcare duties do not stop when you leave for work in the morning or drop your kid at daycare or school. Work/life balance is something that we all struggle with. It is hard to let go and completely shut off from work when you are away from work. We feel that shutting off from work will reflect bad on our attitude and/or engagement level. But if you do not take time to recharge but stay totally focused on work then you will risk burnout and you would not be as effective as you should be.

There are many ways to achieve work/life balance, but we should tailor it to our own needs and requirements. I personally like to give emphasis on time management and prioritizing work load, which helps balance stress as well as the daily activities. Allocating time for family activities like attending your children's sport games as well as spending time with friends certainly helps keep your mind refreshed. Depending on which kind of work you are involved with, setting up rules likes no work weekends or setting a time every night when you stop looking at your work emails can help the mind and body rest and disconnect. Finally, take some time off to take care of yourself and use your vacation days to have some fun.

\section{Who inspired you/guided you in your career/current role?}

We all have role models, who embody the qualities we admire, and we look upon them or emulate them. These are people who we meet when we are growing up, while studying and continued through our career. We meet many associates, friends, coworkers as well as mentors who influence us directly or indirectly. One of the people who inspired me and guided me was my early career manager to whom I look up to with profound respect. One example I can give about the person which inspired me was - he reads a lot of scientific articles as well as journals. If you want to be successful in your field, you should know your field thoroughly, get to know new innovations or future updates currently in your area of expertise. Early career years are very important because they shape your habits, influence your thinking and set you in a positive mindset. Once you know in which direction you want to take your career to, then there are a separate set of people as well as mentors who influence you, since every stage of your career is different. Our positive role models motivate us, teach us and guide us to uncover our own potentials, strengths and weaknesses so we can start overcoming barriers and solve problems more strategically. 


\section{What advice would you give to young women hoping to embark on a career in the field?}

Today, women are in every STEM discipline, in every type of job and represent the widest range of background and experiences. A career in STEM is very dynamic, stimulating, with endless possibilities, numerous opportunities and a supportive environment everywhere. The advice I would give to young women is be curious, positive, open-minded and be ready to learn new skills. There will be obstacles and setbacks but do not get demotivated as any career will have similar challenges. To be successful and to advance in your career, you will need to have enough passion, willingness to work hard, have great mentors on your side and develop a supporting network around you. At the end of the day, you will realize the impact you are making by being in this field can be highly satisfying and rewarding.

\section{Disclaimer}

The opinions expressed in this interview are those of the interviewee and do not necessarily reflect the views of Future Science Group.

\section{Financial \& competing interests disclosure}

The author has no relevant affiliations or financial involvement with any organization or entity with a financial interest in or financial conflict with the subject matter or materials discussed in the manuscript. This includes employment, consultancies, honoraria, stock ownership or options, expert testimony, grants or patents received or pending, or royalties.

No writing assistance was utilized in the production of this manuscript. 
